\title{
Fault Indicators Allocation Using Variable Neighborhood Search Aiming Energy Quality Improvement
}

\author{
Jáder de Alencar Vas- \\ concelos \\ Federal University of \\ Goiás - Brazil \\ jadermat-@ hotmail.com
}

\author{
Antônio César Baleeiro \\ Alves \\ Federal University of \\ Goiás - Brazil \\ abaleeiro@gmail.com
}

\author{
Marcelo Escobar de \\ Oliveira \\ Federal Institute \\ Technology of Goiás - \\ Brazil \\ m.escobar.oli- \\ veira@gmail.com
}

\author{
Luis Gustavo Wesz da \\ Silva \\ Federal Institute \\ Technology of Goiás - \\ Brazil \\ lgwesz@gmail.com
}

\begin{abstract}
Distribution systems are affected by faults that may lead to service interruption, which is inconvenient for the consumers and increases the refund costs payed by the company. Optimizing the allocation of fault indicators devices (FIs) is a promising alternative to improve the energy quality. Using FIs reduce the team's average displacement time to the fault(s) location, which implies reduction on the Equivalent Interruption Duration per Consumer Unit (DEC) indicator. Since the indiscriminate use of FIs is prohibitive, this paper presents the implementation of the metaheuristic routine Variable Neighborhood Search (VNS) to determinate optimized locations to install the FIs, aiming DEC reduction. The results, collected from a real feeder, confirm the proposed methodology`s efficiency.
\end{abstract}

Keywords - Fault Indicator Device, Energy Quality, Metaheuristic, Optimal Allocation.

\section{INTRODUCTION}

The electrical distribution systems networks, in both urban and rural areas, are often affected by faults that, depending on the event's severity and the duration of the service's interruption to the consumers, entails severe consequences to the distribution system's users. Further on, interruptions to the energy supply elevate the company's refund costs, and may compromise the concession's balance.

Due to the exposition of the circuits and equipment to the environment, adverse climatic conditions (atmospheric discharges, contact to tree's branches and other objects) and operational failures, the electrical networks are subjected to contingencies that may lead to service interruption. Although the transmission systems are also subjected to faults, it is highlighted in [1] that about $80 \%$ and $90 \%$ of the faults in the electrical systems are linked to events that occurred in the distribution system.

The Fault Indicator Devices (FIs) were developed as an alternative to reduce the average time of interruptions in distribution system's feeders. The FIs indicate the passage of fault currents, collaborating to the fasten location of defective points. The signalization is mostly done using LEDs that, if installed in adequate locations, eases the problem's visualization. The employment of FIs decreases the average time of search and locating faults, named on PRODIST [2] as TMD, proving to be a convenient device to distribution systems' feeders that usually covers large areas.

Even though the use of FIs is an alternative to keep the continuance indicators on adequate levels, as the DEC (Equivalent Interruption Duration per Consumer Unit), for example, the indiscriminate use and without technical criteria may not result in the expected TMD reduction. Thus, it is required a methodology to allocate the FIs in an optimized way, in other words, a method to indicate the quantity of FIs and their positions along the feeder.

It is examined on [3] the application of the Immune Algorithm to solve the FI allocation problem aiming minimize the costs of nom-supplied energy, also considering the investments needed to acquire the FIs. To show the tool's efficiency the optimized allocation problem is solved for one feeder of Taiwan Power Company.

On [4] it is proposed the FIs allocation based on Genetic Algorithm (GA). The GA's implementation adopts a fitness function that considers the load distribution, the users number and the distance to other devices capable of detecting faults (including protection devices). The paper presents results to allocate FIs in two feeders of Elektro Eletricidade e Serviços $S / A$. However, the methodology has some limitations and particularities, such as: the allocation occurs only in the feeder main branch; the FI insertion considers the simultaneous installation of a maneuver switch (creating new load blocks); the data regarding the fault rate were excluded.

This paper proposes using a metaheuristic optimization methodology known as Variable Neighborhood Search (VNS) [5-6] to guide the FIs' allocation in electrical distribution systems' feeders. Amongst the advantages on implementing the tool, are emphasized: possibility of allocating FIs not only in the feeder main branch, with the option to restrain the allocation to specific parts; new approach on calculating the TMD after the FI insertion, considering the expected time value to locate a fault according to the probabilistic point of view; possibility to evaluate the insertion of an isolated FI, which means installing a FI without a maneuver switch associated to it. The metaheuristic VNS was proved adequate to solving the FI 
allocation problem (FIAP) and presents relatively reduced computational time, considering the FIAP's combinational nature.

This paper is structured as follow: section II defines the relevant variables and expressions to the problem; section III analyses the impact of inserting FIs on the average times and DEC indicator, in the section also is defined the FIAP mathematical model; section IV approaches the VNS method applied to the allocation problem; the results are presented in section $\mathrm{V}$, and the conclusions, in section VI.

\section{Primary Evaluation OF SERVice CONTINUANCE}

It is desirable to estimate a distribution system's service quality based on simple information of the network, it allows previous simulation of network changes and, consequently, contributes to reach higher service quality. The methodology presented in this section evaluates the collective indicators (DEC, FEC) and individual indicators (DIC, FIC), further on the Non-Distributed Energy (NDE), based on network data and characteristics.

The parameters and definitions to support and explain the methodology are presented in [7], some of them:

- $\quad$ Fault ratio, $\lambda_{i}$ : represents the average number of faults in a year per length, the unit is (faults/km)/year or faults/km $\times$ year;

- Load block: group of branches deriving from a switch, the group cannot have another switch linking the branches;

- $\quad$ Fault ration of the i-th load, $\Lambda_{i}$, mathematically defined as:

$$
\Lambda_{i}=\sum_{k=1}^{N_{t r}} l_{i k} \lambda_{i k}
$$

being:

$N_{t r}: \quad$ number of branches in the load block $i$;

$l_{i k}$ : length of the branch $k$ from load block $i$.

- Permanent fault factor: express the relation between permanent faults and total faults in the distribution system, symbolized by $f_{\text {per }}$. A common value to distribution networks is 0,3 (that is, 30 permanent faults for every 100 faults in the system).

The considerations made to estimate the indicators are: the protection devices are correctly coordinated; in the event of a fault, the transference of load blocks between circuits is not considered. The proceeding simulates the occurrence of $\Lambda_{i}$ faults on the i-th load block. According to [7], the fault on the load block has the following implications:

A certain number of consumers, $N_{t 1, i}$, with interrupted power supply for a searching period $t_{1}\left(t_{1}\right.$ is the time from the moment of the fault's occurrence until its location by the maintenance team);

- $\quad$ A certain number of consumers, $N_{t 2, i}$, without power supply for a time $t_{2}$ due to the system isolation needed to repair the fault.

Based on the previous, the contribution to DEC and Frequency of Interruption Duration per Consumer Unit (FEC) from faults on the block $i$ can be calculated using (2) and (3) as follows:

$$
\begin{gathered}
D E C_{i}=f_{\text {per }} \Lambda_{i}\left(\frac{N_{t 1, i} t_{1, i}}{C_{c}}+\frac{N_{t 2, i} t_{2, i}}{C_{c}}\right) \\
F E C_{i}=f_{\text {per }} \Lambda_{i} \frac{N_{t 1, i}}{C_{c}}
\end{gathered}
$$

From the calculated $D E C_{i}$ and $F E C_{i}$ to each block, the global $D E C$ and FEC may be evaluated as shown in (4) and (5):

$$
\begin{aligned}
& D E C=\sum_{i=1}^{N_{b l}} D E C_{i} \\
& F E C=\sum_{i=1}^{N_{b l}} F E C_{i}
\end{aligned}
$$

Considering faults only on the primary voltage network (medium voltage feeders), the individual service continuance indicators are the same to every consumer on a given load block $i$. Thus, to evaluate the indicators DIC and FIC, it is required to determine how many $N_{b l, k}$ blocks affect the block $i$. The individual indicators are calculated as presented in (6) and (7):

$$
\begin{gathered}
D I C_{i}=\sum_{k=1}^{N_{b l, k}} f_{p e r} \Lambda_{k}\left(t_{1, k}+t_{2, k}\right) \\
F I C_{i}=\sum_{k=1}^{N_{b l, k}} f_{p e r} \Lambda_{k}
\end{gathered}
$$

Finally, being $D_{\text {average }, i}$ the $i$ block's annual (or monthly) demand average, the Non-Distributed Energy (NDE) can be obtained as shown in (8):

$$
N D E=\sum_{i=1}^{N_{b l}} D I C_{i} D_{\text {average }, i}
$$

\section{QUALITY INDICATORS EVALUATION CONSIDERING FI'S INSERTION}

According to [8-9], installing $N_{F I}$ FIs in a distribution system feeder implicates on the division of the system in $\left(N_{I F}+\right.$ 1) parts and the time to locate a fault $T_{i}$ for every $i$-th part is calculated using equation (9):

$$
T_{i}=T_{0}\left(\frac{L_{i}}{\sum_{j=1}^{N_{I F}+1} L_{j}}\right)
$$

In this equation, $T_{0}$ is the average tine to locate a fault withouth the FI and $L_{i}$ is the length of the part " $i$ " (or the lengths of branches that compose the part $i$ summed). In this context, part means the group of primary branches between two consecutive FIs or between the substation and the first FI, or even the branch after the furthermost FI.

The following example presents the application of equation (9), the system is shown in figure 1.

Without the FI, the average time to locate a fault is supposed 1 hour $\left(T_{0}=1\right)$, considering the 
substation as the maintenance team's start point of search.



Figure. 1. Simplified radial system with one FI installed

- Considering the FI's installation, the maintenance team must go through only one of the system's parts (before or after the FI). The average time to locating a fault then becomes:

$$
T_{1}=\frac{5}{5+3} 1=0,625 h
$$

and

$$
T_{2}=\frac{3}{5+3} 1=0,375 h
$$

being $T_{1}$ and $T_{2}$ the average time to go through the brach before and afther the FI, respectively.

The study of the FI's influence on estimating the distribution systems' service quality indicators must consider the FI's functionalities characteristics. Since the FI's position interfere on the average locating time, the concept of FI's Cover Region (or simply Region), which is the parts created when the FI is inserted, proposed in [9] becomes important. The concept was applied in [10], but the system's protection devices were unconsidered. Figure 2 illustrates a feeder and highlights its regions and load blocks.

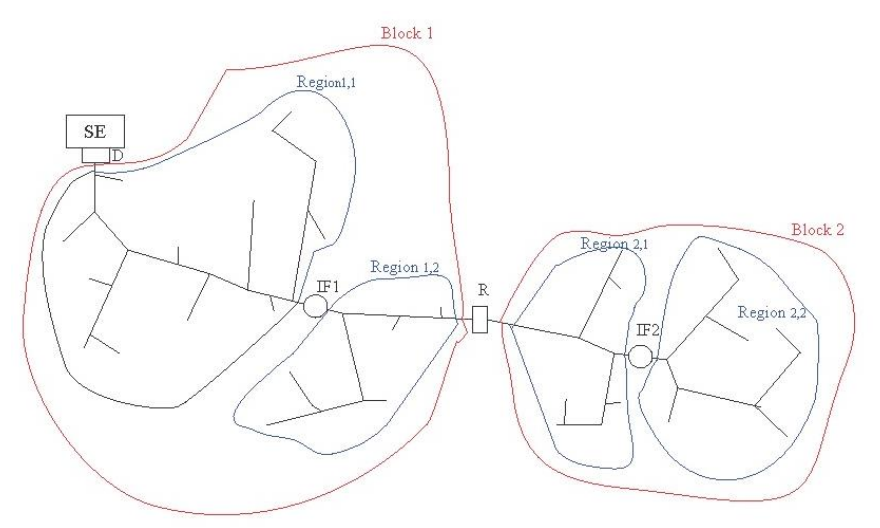

Figure 2. Feeder's regions and load blocks

Naturally, inserting FIs affects the quality indicators related to interruption time $(D E C, D I C$ and $N D E)$. Due to the lack of studies approaching the influence of FIs on the preparation and execution times, only the reduction of the time to locate faults will be considered. Based on these considerations, the average time to locate a fault on distribution networks with FIs can be calculated as the following steps:

1. The installation of $N_{I F}^{i}$ FIs devices in a load block $i$ divides it in $N_{I F}^{i}+1$ regions and the time to locate a fault $\left(T_{i, k}\right)$ to every k-th part can be calculated using (10):

$$
T_{i, k}=T_{0}^{i}\left(\frac{\sum_{j \in \text { Region }_{i, k}} l_{j}}{\sum_{j \in \text { LoadBlocck }_{i}} l_{j}}\right)
$$

2. The fault's probability of occurrence in a region $k$, within the block $i$, must consider the fault ratio, $\lambda_{j}$, of each part:

$$
P_{i, k}=\frac{\sum_{j \in \text { Region }_{i, k}} l_{j} \lambda_{j}}{\sum_{j \in \text { LoadBlock }_{i}} l_{j} \lambda_{j}}
$$

3. The average time of fault location to a block $i$ is calculated as presented in (12):

$$
T_{i}=\sum_{k=1}^{N_{I F}^{i}+1} P_{i, k} T_{i, k}
$$

being:

Region $_{i, k}$ : group of branches that compose the $k$ region of load block $i$;

LoadBlock $_{i}$ : group of branches that compose the block $i$;

$T_{0}^{i}$ : estimated time to locate a fault in the block $i$ without FIs; $l_{j}$ : length of branch $j$;

$\lambda_{j}$ : fault ratio of branch $j$, in (faults $/ \mathrm{km}$ )/year.

From the $T_{i}$ calculation, the quality indicators related to time can be calculated based on (13):

$$
t_{1}(i)=T_{i}+t_{i}
$$

The variable $t_{i}$ from (13) represents the portion spend on phone calls and mobilizing the maintenance team, also called preparation time, as defined on PRODIST's 8th module [2].

Given the relevance of preserving the energy quality indicators levels, as wells as the compensation costs to which the companies are subjective in case of violation, the computational tool presented in this paper aims the reduction of the Equivalent Interruption Duration per Consumer Unit $(D E C)$. The decision to reduce the DEC indicator was made with the objective of improve the supplied energy's quality, moreover reducing the NDE, DEC and DIC indicators results in financial return to the company.

Based on the considerations related to the quality indicator's evaluation in networks with FIs, the optimization problem is formulated (14):

$$
\begin{array}{cccc}
\text { minimize } & f\left(G, V_{F I}\right) & & \\
\text { s.a: } & V_{F I} & \subset & B \\
& n\left(V_{F I}\right) & = & N_{F I}
\end{array}
$$

$B$ is the group of branches that form the network's graph; $V_{I F}$ is the group of branches with FI and the objective function is defined by:

$$
f\left(G, V_{F I}\right)=\frac{f_{p e r}}{C_{c}} \sum_{i=1}^{N_{b l}} \sum_{k=1}^{N_{t r}} l_{i k} \lambda_{i k}\left(N_{t 1, i} t_{1, i}\left(V_{F I}\right)+N_{t 2, i} t_{2, i}\right)
$$

$l_{i k}$ : length of the k-th branch from block $i$;

$\lambda_{i k}$ : fault ratio of the $\mathrm{k}$-th branch from $i$;

$N_{t 1, i}$ : number of users on block $i$ affected for a period $t_{1}$; 
$t_{1, i}\left(V_{I F}\right)$ : sum of average call time and fault search on block $i$, if there is any installed FI in the branches corresponding to the elements of the $V_{I F}$;

$N_{t 2, i}$ : number of users on block $i$ affected for a period $t_{2}$;

$t_{2, i}$ : average time to execute repairs on load block $i$.

The first restriction compels the FI's allocation only in the system B, the second guarantees the allocation of exactly $N_{I F}$ FIs.

\section{VNS APPLIED TO FIAP}

The Variable Neighborhood Search (VNS) is a global optimization metaheuristic proposed by Mladenovic and Hansen on 1997 that performs local search on variable neighborhoods [11]. The metaheuristic routine explores, iteratively, increasingly further neighborhoods to avoid local solutions. The search can also be performed locally and repeatedly to find optimal local solutions.

Since the VNS conception, many variations were proposed, among them the most important are: Reduced VNS, Basic VNS, General VNS and a few other versions such as Skewed VNS, Decomposed VNS and Non-Monotone VNS [5], [6], [11].

It is stressed in [11] the tendency to apply Reduced VNS (RVNS) on problems where the local search takes too much computational time. The RVNS may be used independently or attached to a more complex VNS routine. Due to the use of topologies with many FIs, analyzing neighborhoods using the Basic VNS demands too much computational effort, thus the presented tool uses the Reduced Variable Neighborhood Search.

The RNVS uses nested neighborhoods and evaluates the objective function to elements $x \in X$ generated randomly, until the stop criterium is reached [12]. The figure 3 shows the flowchart that presents the algorithm RNVS applied to the FIAP's solution. The diagram is simplified and omits, for example, the steps of reading and analyzing the system's graph, or the process to obtain the initial solution, which is randomly selected among the feasible solutions.

The objective function handles the evaluation of the current solution, that corresponds to $f\left(G, V_{F I}\right)$ described in (14), and represented as $f\left(V_{F I}\right)$ in figure 3 . If the current solution does not satisfy the equation $f\left(V_{F I}^{\prime}\right)<f\left(V_{F I}^{0}\right)$, the algorithm demands the exploration of neighborhood $N_{2}$, in that case the alteration is given in 2 parts and so on. It is important to explicit that both the branch position to be changed and the value are obtained randomly, but always maintaining the solutions feasible.

To every case the stop criteria used was reaching the Maximum Iteration Number $\left(N_{\text {Iter }}\right)$, the $N_{\text {Iter }}$ value varied between 300 and 6000 depending on the system. The most complex case presented convergence after 2000 iterations.

The maximum number of neighborhoods was set as the number of FIs requested to allocation:

$$
k_{\text {máx }}=N_{I F}
$$

Thus, the neighborhood's evolution process allows the change of all FIs.

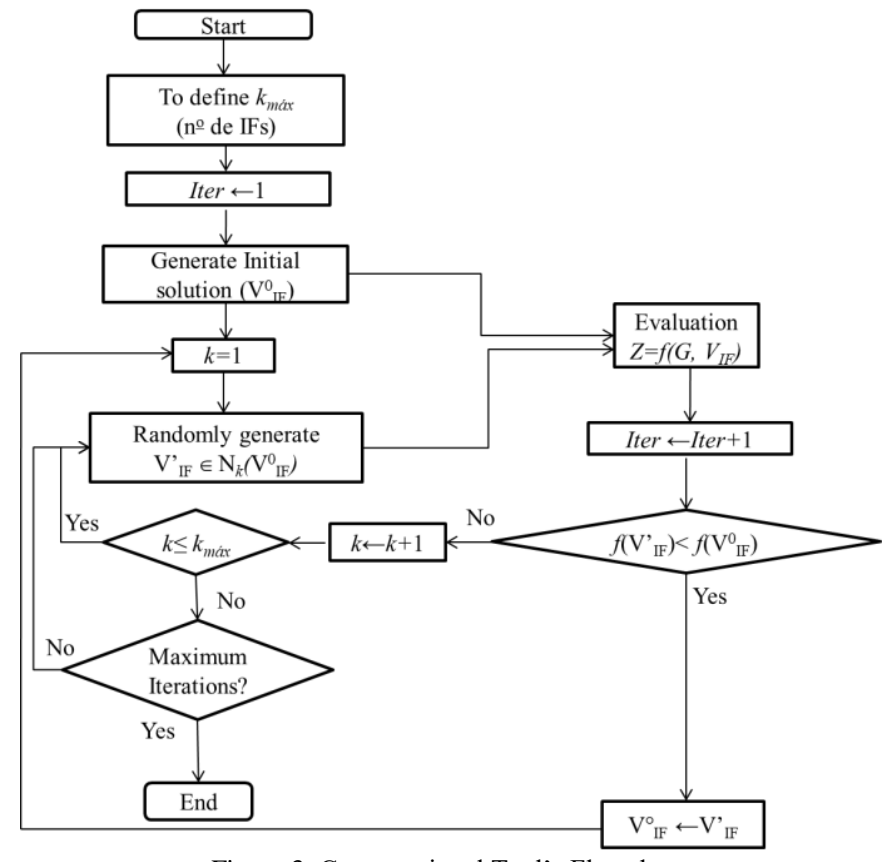

Figure 3. Computational Tool's Flowchart

The current solution $V_{I F}$ presents the group of all branches eligible to the FI installation. It was used direct codification as follows:

$$
V_{F I}=\{42 ; 256 ; 3102 ; 9274\}
$$

When solving the FIAP, according to the implemented algorithm RVNS, it is defined that exploring the first neighborhood of $V_{F I}$ means randomly changing one of its branches. The new branches are chosen among the eligible branches, areas with difficult access may be excluded (such as marshes, private areas, forests).

The program presented in figure 3 was tested using a real feeder. Six situations varying the quantity of FIs from 1 to 6 and the results are presented in section V. An economic analysis of the simulated situations should lead to the most rentable option to the company.

\section{RESUlTS FOR A REAL ELECTRICAL DISTRIBUTION SYSTEM}

To validate the proposed methodology, it is necessary to apply it to a case study, the present tool was tested solving the FIAP of a real feeder, that belongs to the company CELG Distribuição S.A. The feeder's diagram is shown on figure 4.

Using the proposed methodology, the program's entry is the number of FIs to allocate, which was varied from 1 to 6 and the results obtained at the end of the iterations, to every situation, were saved. The table I shows the branches selected by the VNS at the end of the iterations to each simulated situation. 


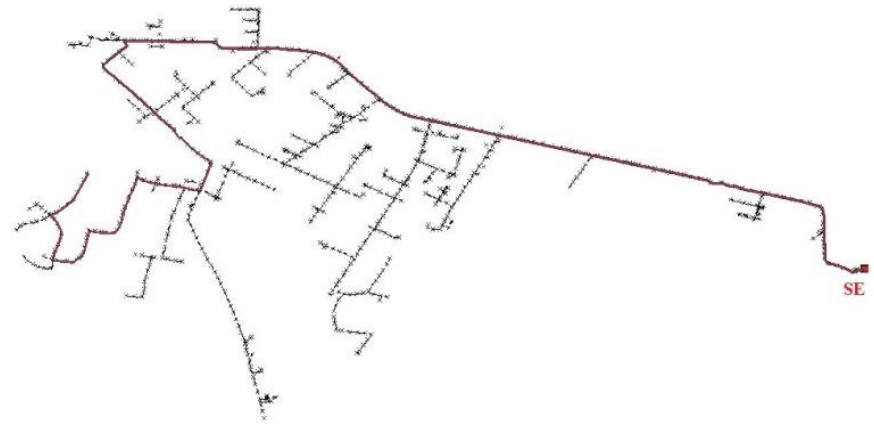

Figure 4. Test system with highlighted main branch

TABLE I. TEST SYSTEM'S RESULTS

\begin{tabular}{cc}
\hline \# FIs & Selected branches \\
\hline 1 & 2284 \\
2 & 3886,2284 \\
3 & $3886,3102,2226$ \\
4 & $3882,3102,3526,2226$ \\
5 & $3886,107,294,4516,2865$ \\
6 & $3882,872,3526,4516,9293,2284$ \\
\hline
\end{tabular}

The test considering three (3) FIs installed in the feeder is illustrated in figure 5 . A comparison between figures 4 and 5 shows that, the found solution uses a point out of the main trunk: branch 3102 (or 3104-3102), which would not be possible according to some methodologies, such as the one presented in [4]. To the cases with 4, 5 and 6 FIs, some allocations are out of the main trunk, for 5 and 6 FIs, 2 of them are allocated in branches. The allocation in branches emphasizes this methodology's importance, since limiting the allocation to the main trunk would lead to solutions farther from the FIAP's global optimum point.

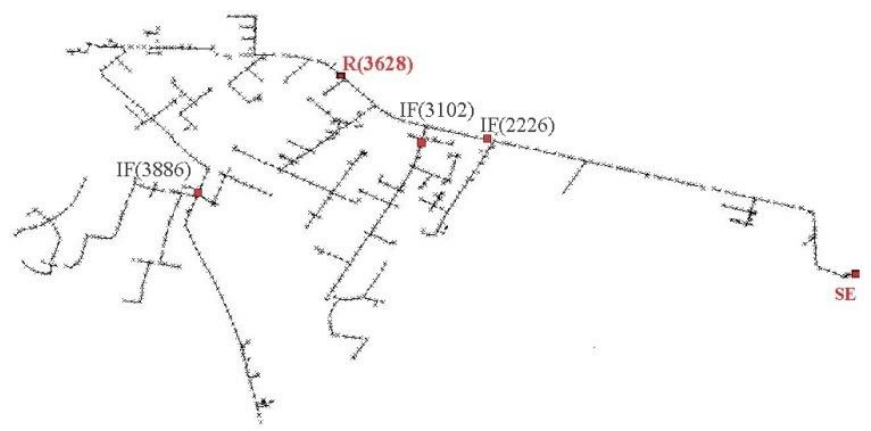

Figure 5. FIAP Solution Using 3 FIs

The solution's economic analysis obtained by the VNS routine consists on the evaluation of the Present Liquid Value (PLV) and Payback. The PLV is calculate by representing the sum of all the current expenses and revenues, represented in (16). The Payback indicates the time required for the revenue value to surpass the initial investment.

$$
P L V=-I_{0}+\sum_{t=1}^{q} \frac{F C_{t}}{(1+i)^{t}}
$$

Where: $I_{0}$ represents the initial investment, that is, the price to acquire the FIs; $i$ is the Minimum Attractivity Rate (MAR); $t$ is the time, limited to the FIs lifespan, in years; $F C_{t}$ represents the cash flow: revenues (NDEC reduction) minus the expenses (maintenance or purchase of devices).

This paper uses as fault indicator device the Navigator-LM made by Horstmann. This FI has unitary value R $\$ 2.400,00$. The device is projected to operate in networks with maximum voltage $161 \mathrm{kV}$ and has two Lithium replaceable batteries, with lifespan 15 to 20 years. The FI also has a battery controller with luminous indication for low autonomy.

Since the device does not need periodic maintenance, the analysis considers only eventual maintenance, about $2,5 \%$ of the product value. The installation cost is set as $5 \%$ of the product's cost, that includes the team's displacement costs and other occasional costs. The value considered as fare is $\mathrm{R} \$ 423,50 / \mathrm{MWh}$, which is homologated by ANEEL as the average fare, without the company's (CELG D) taxes, for 2016.

The considered interruption cost corresponds only to the Non-Distributed Energy Cost (NDEC), despising the other costs reductions, such as the penalties for individual indicator's violation.

Based on these considerations, the table II was created presenting estimated DEC data, estimated NDE and NDEC reduction for each solution pointed in table I.

\begin{tabular}{ccccc}
\multicolumn{4}{c}{ TABLE II. Estimated IndicATORS AND COSTS FOR TEST SYSTEM } \\
\hline $\begin{array}{c}\text { Estimated } \\
\text { FIs }\end{array}$ & $\begin{array}{c}\text { DEC Reduc- } \\
\text { tion (hours) }\end{array}$ & $\begin{array}{c}\text { Estimated } \\
N D E \\
\text { (hours/year) }\end{array}$ & $\begin{array}{c}\text { NDEC Re- } \\
\text { duction } \\
(\mathrm{RW} \$)\end{array}$ \\
\hline 0 & 23,123 & 0 & 164,83 & 0 \\
1 & 22,092 & 1,031 & 157,48 & $3.112,73$ \\
2 & 21,647 & 1,476 & 154,30 & $4.459,46$ \\
3 & 21,272 & 1,851 & 151,62 & $5.594,44$ \\
4 & 21,124 & 1,999 & 150,58 & $6.034,88$ \\
5 & 20,981 & 2,142 & 149,56 & $6.466,85$ \\
6 & 20,845 & 2,278 & 148,52 & $6.907,29$ \\
\hline
\end{tabular}

Using the table II data, the PLV was calculated to the 7 situations, considering a 15 years period. The MAR value is set as $11,25 \%$, which was the Brazilian basic interest rate in May/2017. The results are presented in figure 6.

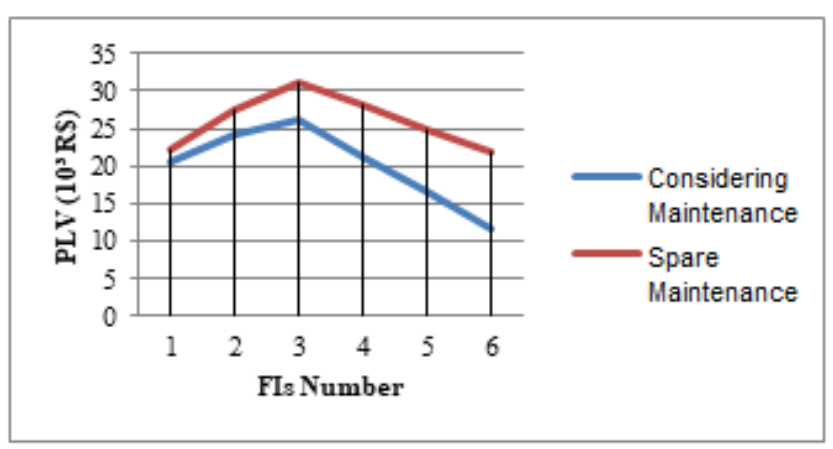

Figure 6. PLV according to the FI cost

Analyzing the figure 6, the solution that presents the greatest financial feedback is the option using 3 FIs. The best solution using 3 FIs has a $D E C_{\text {estimated }}$ equal to 21,27 hours, with $v_{I F}=$ $\{3886,3102,2226\}$. Even when the maintenance costs are not considered, the solution with best economic response is the same.

The payback time, using the solution obtained by the VNS routine to allocate 3 FIs and considering the maintenance costs 
is 5,1648 years ( 5 years and 2 months). When the maintenance costs are despised, the payback time becomes 4,5908 years (4 years and 7 months).

Including the costs due to compensation payments for individual continuance indicators could change the best solution, especially considering the type of feeder that generates high compensation costs, such as this one (on 2015, more than $\mathrm{R} \$ 70.000,00$ in compensation were payed, considering $D I C$ and $D M I C$, due to this feeder).

\section{CONCLUSION}

The implemented VNS methodology was validated through a case study that represents the real conditions of a feeder owned by the company CELG D. The simulation, showed on section $\mathrm{V}$, pointed that it is possible to reduce the feeder's $D E C$ indicator in 1,85 hours/year ( $8 \%$ ) by employing 3 FIs, which implies an investment of $\mathrm{R} \$ 21.000$ with payback period of 5 years and 2 months, at most.

The results confirm that the FIs are feasible alternatives to improve the service quality indicators. The methodology also demands low investments costs. As mentioned above, the costs analysis may be improved by adopting a method capable of estimating the compensation costs of reduction of the individual indicators, especially DIC. The improved tool may prove the economic viability of employing more FIs, primarily on systems where the compensation costs represent great values.

\section{REFERENCES}

[1] JAHEDI, A.; JAVIDAN, J.; NASIRAGHDAM, H. Multi-objective modeling for fault indicators placement using of NSGA II to reduce off time and costs in distribution network. International Journal of Engineering Research an Applications. p. 106-111. December 2014.

[2] ANEEL. "Procedimentos de distribuição de energia elétrica no sistema elétrico nacional" - PRODIST, Módulo 8 - Qualidade da Energia Elétrica, 2015

[3] HO, Chin-ying; LEE, Tsung-en; LIN, Chia-hung. Optimal placement of fault indicators using the Immune Algorithm. IEEE Trans. on Power Syst., v. 26, n. 1, p.38-45, February 2011.

[4] USIDA, W. F. Sistema inteligente para alocação eficiente de dispositivos indicadores de falta em alimentadores de distribuição. 2011. $234 \mathrm{f}$. Tese (Doutorado) - Departamento de Engenharia Elétrica, Universidade de São Paulo, São Carlos-SP, 2011.

[5] HANSEN, P.; MLADENOVIC, N. (2003). A tutorial on variable neighborhood search, Le cahiers du GERARD G-2003: 46.

[6] HANSEN, P.; MLADENOVIC, N. Variable neighborhood search: principles and applications. European Journal of Operational Research. Montreal, Canada, p. 449-467. 1 jul. 1999.

[7] KAGAN, N.; OLIVEIRA, C. C. B. de; ROBBA, E. J. Introdução aos sistemas de distribuição de energia elétrica. São Paulo: Blucher, 2005. 328 p.

[8] HENDI, R. B.; SEYED-SHENEVA, Seyed-jalal; GANDOMKAR, M Electrical distribution system reliability improvement by optimal placement of fault indicators using Immune Algorithm. International Journal of Engineering Research an Applications, p. 1383-1390. mar. 2012.

[9] VIDYSAGAR, E.; P.V.N. PRASAD; FATIMA, A. Reliability improvement of a radial feeder using multiple fault passage indicators. Elsevier Energy Procedia, v. 14, p. 223-228, 2012.

[10] DASHTI, R.; SADEH, J. Fault indicator allocation in power distribution network for improving reliability and fault section estimation. In: The International Conference on Advanced Power System Automation and Protection, Beijing, China. 2011.

[11] MARTINS, W. A. Busca em vizinha variável aplicado na solução do problema de planejamento da expansão do sistema de transmissão de energia elétrica. 2009. 85 f. Dissertação (Mestrado) - Departamento de Engenharia Elétrica, Universidade Estadual Paulista "Júlio de Mesquita Filho", Ilha Solteira - SP, 2009.

[12] SANTOS, N. M.; OCHI, L. S.; BRITO, J. A.; SEMAAN, G. S. Metaheurísticas GRASP e VNS para problema de grafo com restrições de capacidade e conexidade. In: Simpósio Brasileiro de Pesquisa Operacional (SBPO), 2015. Porto de Galinhas, PE, 2015. 